\title{
Eisenmenger syndrome with left main compression syndrome: a case report
}

\author{
Charlotte Johanna Cool ${ }^{*}$ (D) Fathy Fathini ${ }^{2}$, Ibnu Adams ${ }^{3}$, Aninka Saboe ${ }^{3}$, Nuraini Yasmin Kusumawardhani ${ }^{4}$, \\ Astri Astuti ${ }^{4}$ and Achmad Fauzi Yahya ${ }^{3}$
}

\begin{abstract}
Background: Left main coronary artery disease secondary to pulmonary artery compression related to Eisenmenger syndrome is an under-suspected condition that can cause fatal outcomes if left untreated. It presents with typical angina but is frequently mistaken for pulmonary hypertension $(\mathrm{PH})$ symptoms. It is now recognized as one of the few important causes of angina in $\mathrm{PH}$.
\end{abstract}

Case presentation: A 37-year-old man with a history of unoperated atrial septal defect and Eisenmenger syndrome came to the outpatient department with a chief complaint of angina on exertion. Electrocardiogram showed regular sinus rhythm with right axis deviation, right ventricular hypertrophy, deep T-wave inversion in inferior and anterior leads suggestive of ischemia or strain, and incomplete right bundle branch block. Cardiac CT showed compression of the left main coronary artery due to a dilated main pulmonary artery. Therefore, this patient was diagnosed with Eisenmenger syndrome with left main compression due to dilated pulmonary artery. He was treated successfully with IVUS-guided stent implantation. The patient experienced marked improvement in regular activities, with no recurrence of angina symptoms. Angiography 3 months after the procedure revealed good patency of the stent, without significant stenosis.

Conclusions: Left main coronary artery compression is a complication that should be suspected in patients with Eisenmenger syndrome presenting with angina symptoms. Non-invasive modalities are recommended for diagnostic evaluation, but the gold-standard technique remains coronary angiography. The best treatment is not well-established, with either myocardial revascularization or $\mathrm{PH}$ treatment, but a left main coronary artery stenting procedure is considered an ideal emergent treatment to provide a better quality of life for patients in this condition.

Keywords: Pulmonary hypertension, Eisenmenger syndrome, Left main coronary artery disease, Coronary artery compression

\section{Background}

Eisenmenger syndrome is the most severe form of pulmonary hypertension $(\mathrm{PH})$ in congenital heart disease (CHD). Patients with Eisenmenger syndrome generally present with typical signs such as cyanosis followed by

\footnotetext{
*Correspondence: charlotte@unpad.ac.id

${ }^{1}$ Congenital Heart Disease Division, Department of Cardiology

and Vascular Medicine, University of Padjadjaran, Hasan Sadikin General

Hospital, Jl. Pasteur No. 38, Bandung 40161, Indonesia

Full list of author information is available at the end of the article
}

dyspnoea or angina on exertion. Angina in PH has various aetiologies, such as mitral valve disease, disorders of the lungs, pulmonary artery (PA) disorders and congenital malformations. However, angina is also a common manifestation of a mechanical complication in $\mathrm{PH}$ : left main coronary artery (LMCA) compression. This condition increases the risk of sudden death due to myocardial territory at risk, and therefore may worsen the prognosis. It is usually an under-suspected and under-reported cause of angina, but the incidence is high, ranging from 
19 to $44 \%$ [1]. Early recognition is the key to early management to improve patient outcomes.

Here we describe a case report of an unoperated atrial septal defect (ASD) patient with Eisenmenger syndrome who experienced LMCA compression due to a dilated main PA. This report will highlight the diagnostic workup and best possible management.

\section{Case presentation}

In this case report, we present a 37-year-old man with known unoperated secundum ASD and Eisenmenger syndrome. The patient was diagnosed for the first time 6 months before, with symptoms of typical angina on exertion that had worsened for the last 2 months. He was referred due to resource limitations from another hospital to the CHD division for follow-up in the cardiology department outpatient clinic and underwent scheduled examination. The patient had no other medical history, no family history of congenital disease and no prior invasive procedures. Physical examination showed a cyanotic appearance with finger clubbing, $86 \%$ oxygen saturation by peripheral pulse oximetry, signs of right heart congestion, cardiomegaly, accentuated P2, and pansystolic murmur at the lower left sternal border, with Carvallo's sign on auscultation. The haematology parameters showed secondary erythrocytosis with a haemoglobin level of
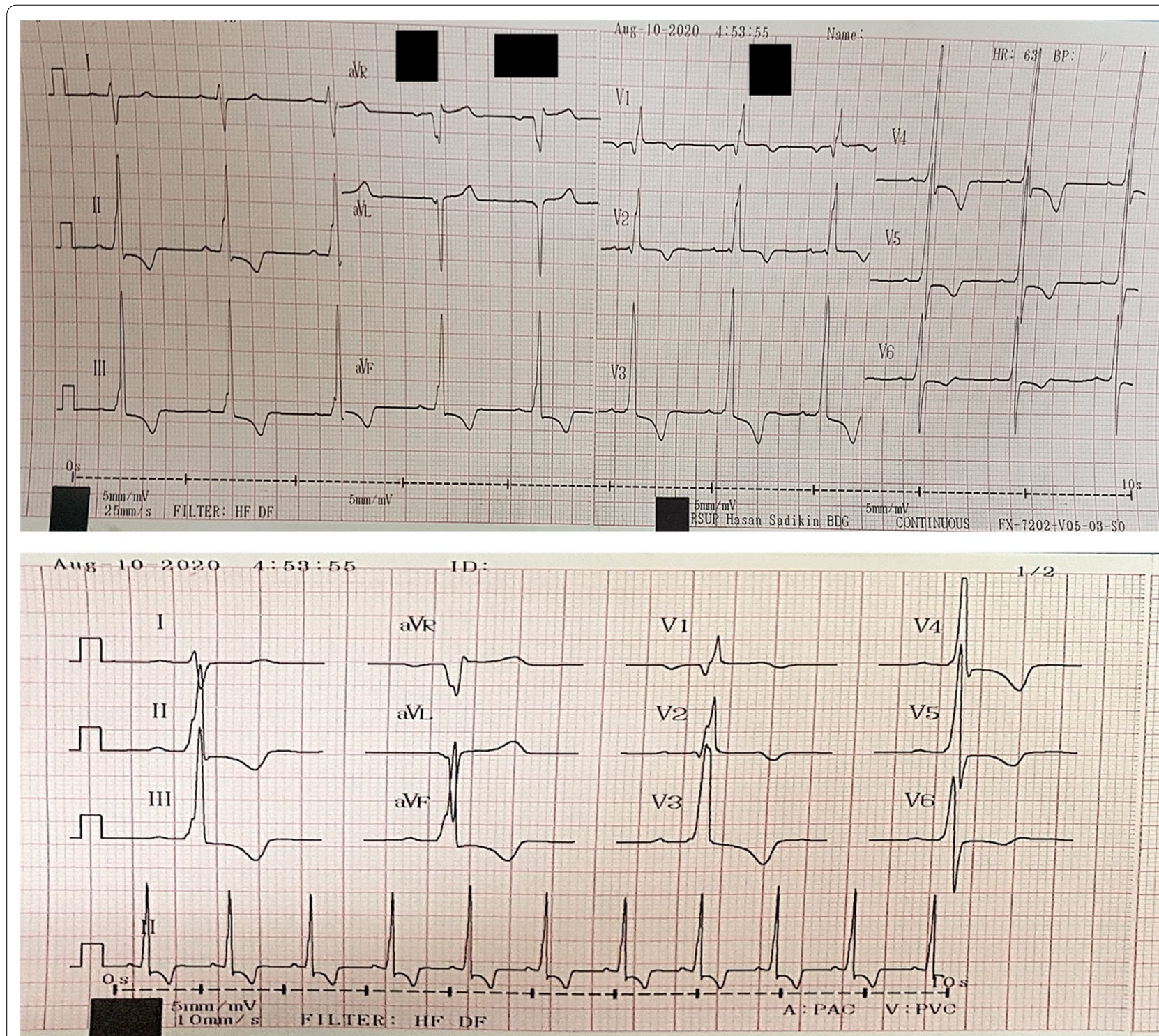

Fig. 1 ECG showed regular sinus rhythm with RAD, RVH, deep T-wave inversion in inferior and anterior leads suggestive of ischemia or strain, and incomplete RBBB 


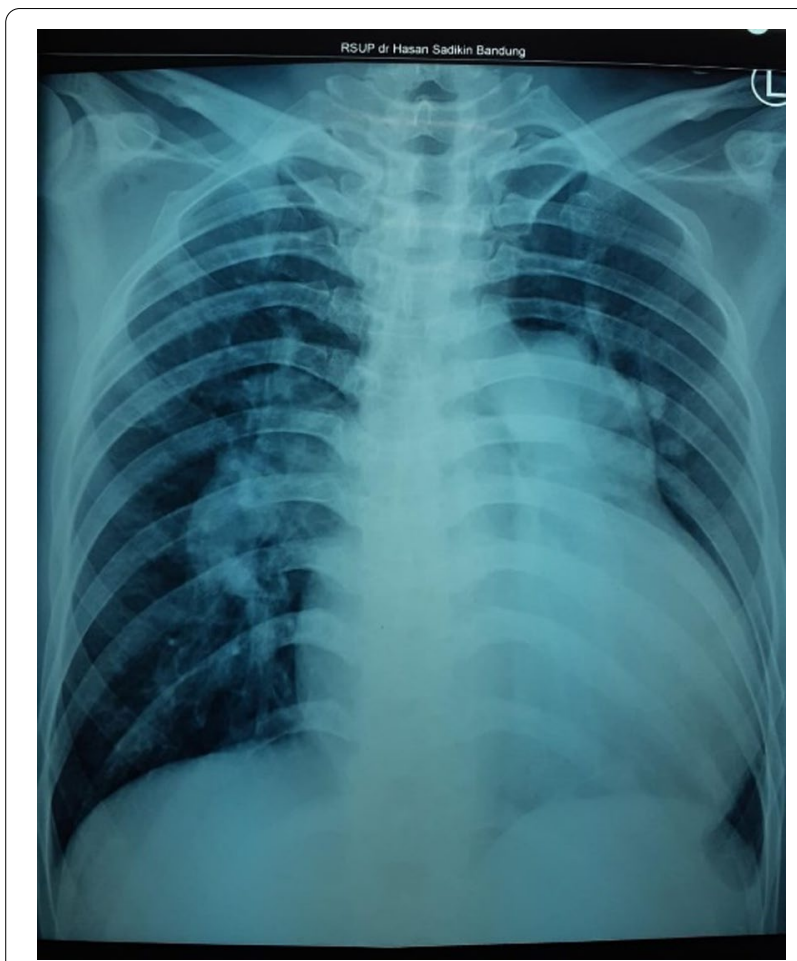

Fig. 2 Thorax X-ray showed cardiomegaly with prominent pulmonary conus and increased pulmonary vascularity

$19.5 \mathrm{~g} / \mathrm{dL}$ and a haematocrit fraction of $55.5 \%$. Electrocardiogram (ECG) showed a regular sinus rhythm with right axis deviation (RAD), right ventricular hypertrophy $(\mathrm{RVH})$, deep T-wave inversion in the inferior and anterior lead suggestive of ischemia or strain, and incomplete right bundle branch block (RBBB; Fig. 1). Chest X-ray showed cardiomegaly with prominent pulmonary conus and increased pulmonary vascularity (Fig. 2). Transthoracic echocardiography (TTE) revealed secundum ASD with bidirectional shunt, mainly right to left ( $\mathrm{R}$ to $\mathrm{L}$ ) shunt, D-shaped left ventricle (LV), dilation of the right chamber (right atrium $[\mathrm{RA}]$ and right ventricle $[\mathrm{RV}]$ ) and left atrium (LA), normal systolic function with paradoxical septal movement, moderate tricuspid regurgitation (TR), and a marked dilated main PA (diameter of $48 \mathrm{~mm}$; Fig. 3). The TTE examination conclusion based on ESC guidelines for the diagnosis and treatment of $\mathrm{PH}$ was secundum ASD with a high probability of $\mathrm{PH}$ and marked main pulmonary artery (MPA) dilation.

Based on the presented data, the patient was scheduled for elective right heart catheterization (RHC), as well as angiography due to suspected ischemia suggesting a mechanical complication due to marked dilation of the PA. The RHC revealed secundum ASD with bidirectional (mainly $\mathrm{R}$ to $\mathrm{L}$ ) shunt, mean pulmonary artery pressure (mPAp) pre-oxygen test of $78 \mathrm{mmHg}$ decreasing to $70 \mathrm{mmHg}$ after oxygen test, with low flow (flow ratio pre-oxygen test of 0.98 and post-oxygen test of 1.09) and high resistance (pulmonary vascular resistance preoxygen test of 35.3 decreasing to 31.1 Wood units after oxygen test), with a non-reactive oxygen test as the conclusion. Angiography (Fig. 4A) revealed severe stenosis at the ostium part of the LMCA, without significant stenosis at other coronary arteries. To confirm the diagnosis, the patient was then sent to the radiology department and underwent a contrast-enhanced computerized tomography (CT) scan. The cardiac CT (Fig. 5) showed a dilated MPA $(56.8 \times 51.9 \mathrm{~mm}$ in diameter), MPA-toaorta ratio of $>1.5$, left main (LM) take-off angle of $32^{\circ}$ and severe LMCA compression. Based on coronary angiography and cardiac CT findings, the patient was then referred to a coronary interventionist for further assessment and intervention. Intravascular ultrasound (IVUS) evaluation showed dynamic compression in the ostium LM without atherosclerosis (Fig. 4B, C). After a thorough examination, the patient was diagnosed with LM compression syndrome due to dilated pulmonary artery caused by the severe form of PH Eisenmenger syndrome.

Percutaneous coronary intervention (PCI) with a newgeneration zotarolimus-eluting stent, size $4.5 \times 22 \mathrm{~mm}$, was successfully implanted with IVUS guidance, and the evaluation showed good stent placement (Fig. 6A, B). The patient was discharged after 7 days of hospitalization with no complication and given dual antiplatelet therapy ( $81 \mathrm{mg}$ of acetylsalicylic acid and $75 \mathrm{mg}$ of clopidogrel once daily). PH was treated with a combination of sildenafil, a potent and selective inhibitor of phosphodiesterase type 5; and beraprost, a prostacyclin analogue. On clinical follow-up a week and then a month after hospitalization, the patient showed no recurrence of angina symptoms and was scheduled for evaluation 3 months after the procedure. Angiography evaluation after 3 months revealed no significant stenosis and good patency of the stent. The patient underwent routine follow-up in the outpatient clinic of the CHD division, with marked improvement in regular activities and good compliance.

\section{Discussion and conclusions}

Eisenmenger syndrome is a severe form of $\mathrm{PH}$ associated with acyanotic $\mathrm{CHD}[2,3]$. A persistent haemodynamic condition in chronic $\mathrm{PH}$ may further cause PA dilation due to increased PA pressure (PAp), based on Laplace's law $[1,4]$. PA dilation is present in around $76.6 \%$ of patients with severe $\mathrm{PH}$ [5]. Assessment using non-invasive imaging modalities is recommended to evaluate $\mathrm{PH}$ parameters, including PA diameter. TTE can measure the PA diameter at end-diastole from the parasternal shortaxis view just before the bifurcation, with a normal value 


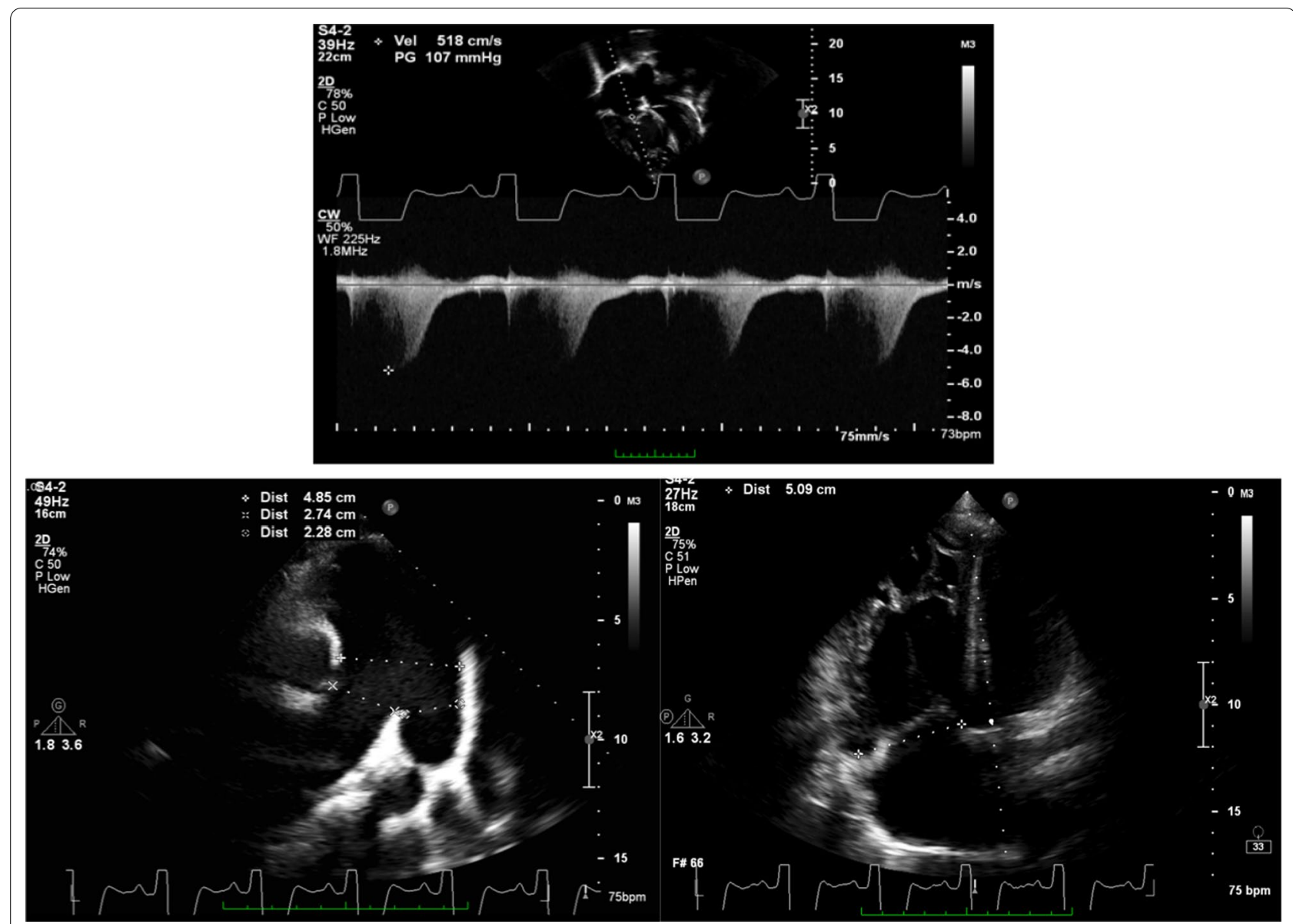

Fig. 3 Transthoracic echocardiography images showed high probability of $\mathrm{PH}$, (upper) with peak TR velocity of $5.1 \mathrm{~m} / \mathrm{s}$, (lower left) dilated MPA of $48 \mathrm{~mm}$, (lower right) dilated RV of $51 \mathrm{~mm}$

of less than $25 \mathrm{~mm}[1,6]$. In case of any difficulties in determining the value precisely, a contrast-enhanced $\mathrm{CT}$ scan is also suggested to identify $\mathrm{PH}$ parameters [5].

Angina symptoms in $\mathrm{PH}$ are important clinical features. The differential diagnosis of angina is extensive, and the characteristics of $\mathrm{PH}$ resemble angina pectoris in general and in location, radiation, intensity, quality and tendency to be initiated by physical exertion. The mechanism of angina is usually due to unmatched metabolic demands caused by reduced coronary perfusion and the pressure gradient of the RV and PA. This can be caused by different underlying diseases, such as mitral valve stenosis; lung disease, especially asthma or emphysema; pulmonary embolism; or CHD [7, 8]. In some cases, the angina presentation may be related to a mechanical complication of $\mathrm{PH}$, and Table 1 lists some other common complications $[3,8,9]$.

Coronary artery disease (CAD) in $\mathrm{PH}$ patients presenting with angina is often under-suspected and usually diagnosed as a coincidence finding. It is now recognized as a serious mechanical complication of $\mathrm{PH}[2]$. CAD pathophysiology is commonly secondary to atherosclerotic disease, but another known condition responsible is $\mathrm{PH}$, which involves extrinsic compression of the LMCA due to dilation of the PA. Extrinsic compression occurs due to a closed anatomic relationship between two structures: the MPA and LMCA $[10,11]$. The MPA serves as a short and wide pipe that normally travels along the left of the ascending aorta and bifurcates just below the aortic arch to form the right and left PA [12]. Among the adjacent structures are the coronary arteries, which originate from the aortic sinuses of the aorta and pass alongside the pulmonary trunk [13].

LMCA compression by an enlarged PA in patients with PH was first described in 1957 by Corday et al. [14]. The prevalence rate was around 40\%, especially if accompanied by angina symptoms [15]. These cases were rarely reported, due to under-diagnosis despite its high incidence [10]. We find some similar conditions previously reported in case reports (Table 2). The mechanism of 

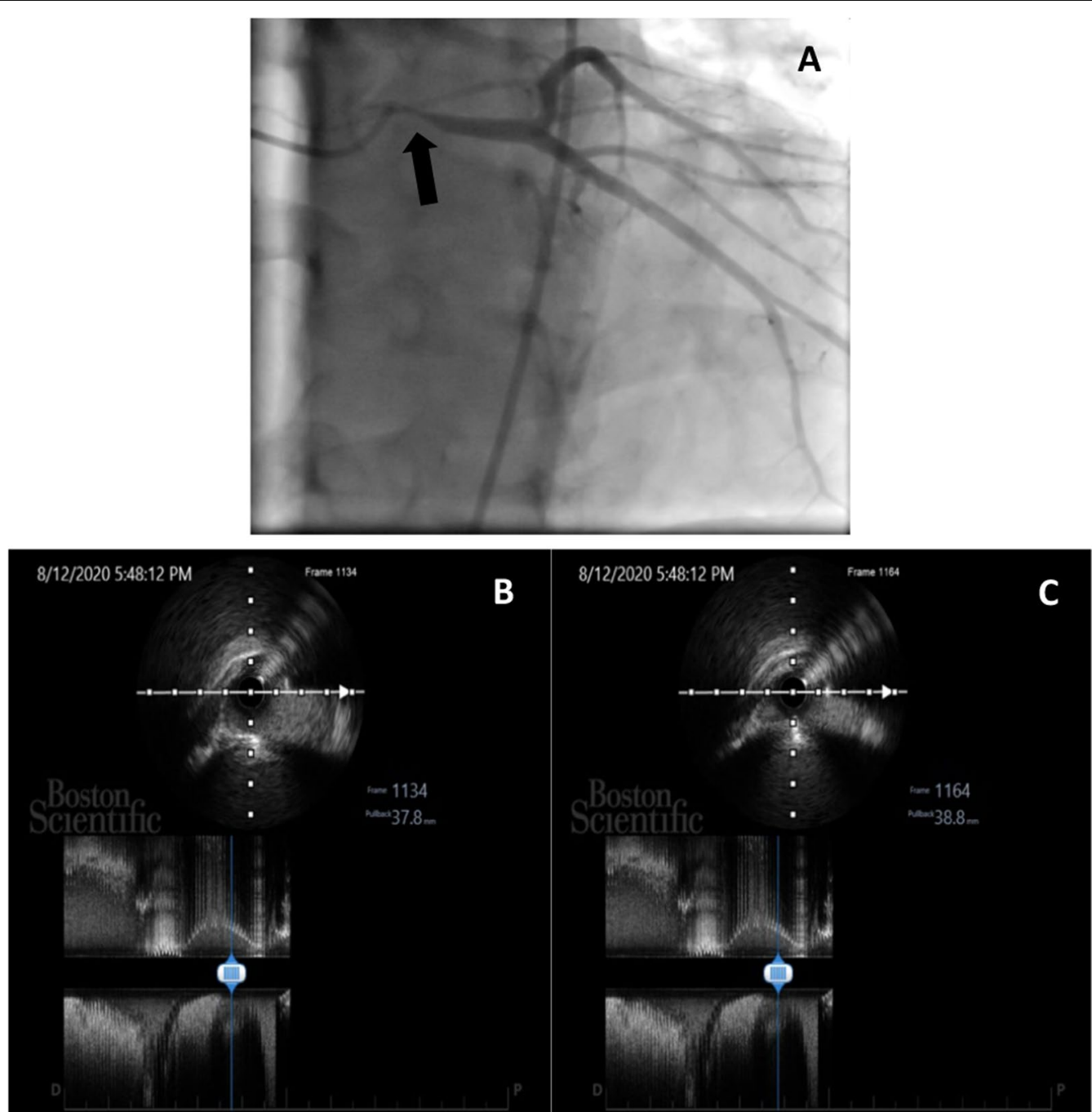

Fig. 4 A Angiography showed severe LMCA stenosis in LAO-caudal view; B, C IVUS evaluation showed dynamic compression of LMCA

angina in this condition is still uncertain. Progressive increases in Pap and RV overload, along with myocardial ischemia caused by artery compression, are proposed as possible mechanisms [9].

Diagnostic modalities regarding this condition are fundamental. Contrast-enhanced CT should be performed to define the PH parameters, especially MPA dilation, and define the LM compression $[1,15,16]$. The compression risk is related to some strong predictors measured by contrast-enhanced $\mathrm{CT}$, such as PA diameter $>40 \mathrm{~mm}$, ratio of the MPA and aortic root $\geq 1.5$, and take-off angle $<45^{\circ}$ (formed between the longitudinal line of the LMCA and orthogonal line of the aortic valve) $[15,17]$. It is also determined by the anatomic relationship between the PA and the origin of the LMCA [18]. The accuracy of those predictors is somewhat favourable: the sensitivity and specificity for LM compression due to PA dilation $>40 \mathrm{~mm}$ are $83 \%$ and $70 \%$, respectively. The MPA-to-aorta ratio has a sensitivity of $73 \%$ and a specificity of $70 \%$, respectively, for predicting compression [15]. Nevertheless, the gold standard of modalities to confirm LM stenosis remains coronary angiography, particularly guided by IVUS [16, 19]. In our case, we found all the strong predictors for compression risk, such as marked dilation of the main PA (diameter $54 \mathrm{~mm}$ ), MPA-to-aorta ratio $>1.5$, and LM take-off angle $32^{\circ}$. All parameters were measured from cardiac $\mathrm{CT}$, which also confirmed severe LMCA compression.

The best management for LMCA compression by PA dilation is not well-established due to the small number of cases reported, but emergent treatment is required due to the high mortality risk. Treatment of the $\mathrm{PH}$ itself and coronary revascularization is the optimal choice [9, 11]. However, the rapid improvement of PA dilation after 

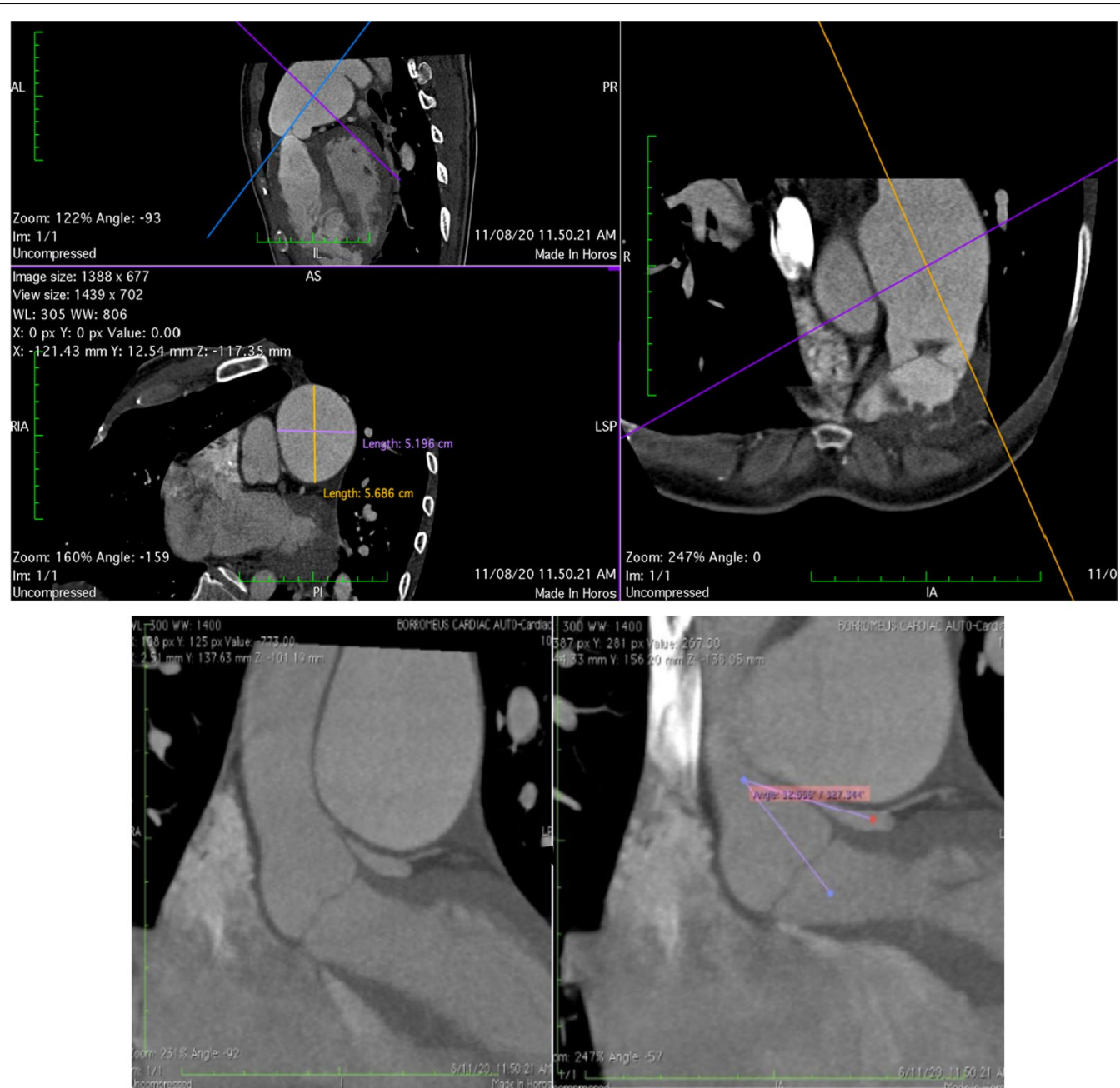

Fig. 5 Contrast-enhanced cardiac CT images, (upper) images showed dilated MPA of $56.8 \times 51.9$ mm, (bottom left) black arrows showed severe compression of LMCA and (bottom right) LM take-off angle of $32^{\circ}$

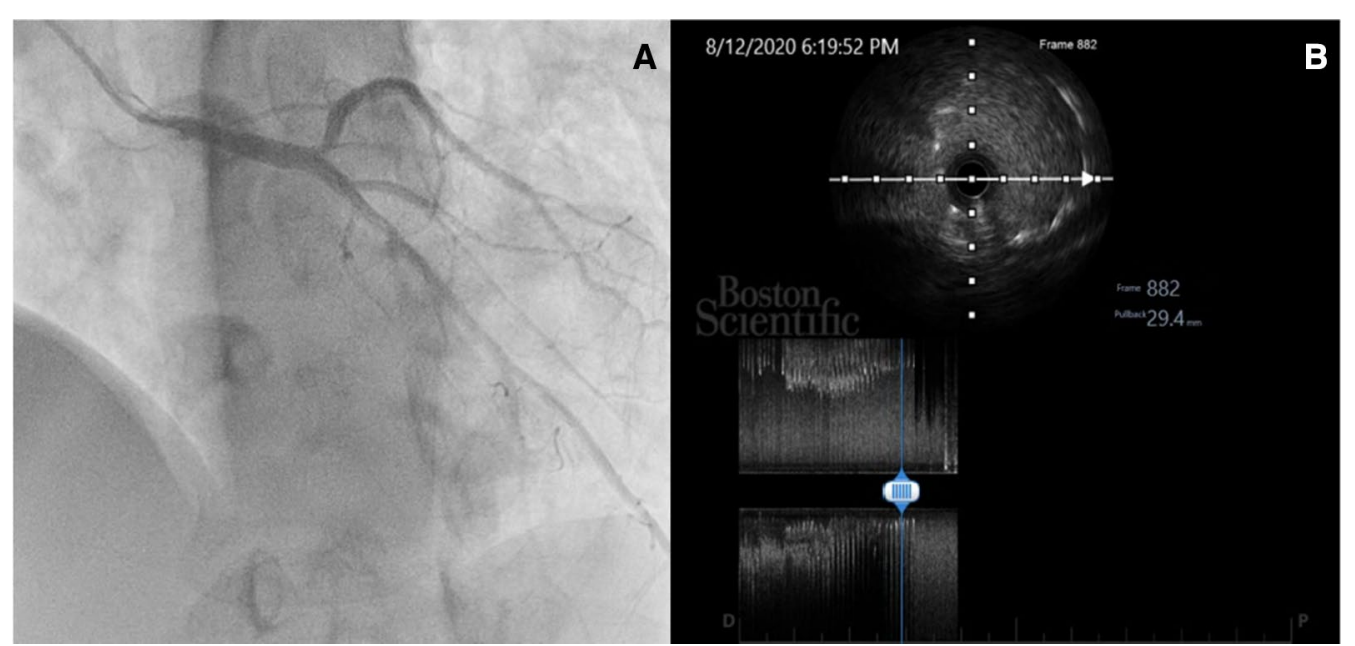

Fig. 6 A Successful PCl of the LMCA in LAO-caudal view; B IVUS evaluation post-PCI of LM 
Table 1 Common complications of Eisenmenger syndrome. [3, 31, 32]

\begin{tabular}{|c|c|c|}
\hline No & Complications & Signs and symptoms \\
\hline 1 & Secondary erythrocytosis & Hyperviscosity symptoms \\
\hline 2 & Haemostasis abnormalities (increased risk in both bleeding and thrombosis) & $\begin{array}{l}\text { Pulmonary bleeding (rupture of hypertrophied bronchial arteries) } \\
\text { Pulmonary embolism } \\
\text { Deep vein thrombosis (DVT) } \\
\text { Stroke or brain abscess }\end{array}$ \\
\hline 3 & Arrhythmias & $\begin{array}{l}\text { Ventricular arrhythmias (ventricular tachycardia [VT] or ventricular } \\
\text { fibrillation [VF]) } \\
\text { Supraventricular arrhythmias (atrial fibrillation [AF] or atrial flutter } \\
{[\text { Afl]) }}\end{array}$ \\
\hline 4 & Endocarditis & Fever \\
\hline 5 & $\begin{array}{l}\text { Mechanical complications } \\
\text { Compression of LMCA }\end{array}$ & Chest pain (angina-like or not) \\
\hline 6 & PA aneurysms, rupture and dissection & $\begin{array}{l}\text { Acute dyspnoea on exertion } \\
\text { Haemodynamic decompensation } \\
\text { Sudden death }\end{array}$ \\
\hline 7 & Compression of intrathoracic structures (recurrent laryngeal nerves) & Hoarseness \\
\hline 8 & Cerebral hypoperfusion due to low cardiac output & Syncope \\
\hline 9 & Renal dysfunction & $\begin{array}{l}\text { Reduced urine output } \\
\text { Hyperuricaemia }\end{array}$ \\
\hline
\end{tabular}

adequate management is impossible; therefore, an urgent approach is needed to improve survival. Recent evidence shows that coronary stenting is a possible option to resolve LM compression [12, 24, 25]. An isolated lesion involving the ostium or shaft of the LM is a class II recommendation for PCI, whereas more complex lesions are best treated with a surgical bypass procedure. Coronary artery bypass graft (CABG) also involves a higher risk in general anaesthesia and cardiopulmonary bypass (CPB) in patients with underlying $\mathrm{PH}$, so $\mathrm{PCI}$ is the preferred strategy. A drug-eluting stent (DES) is preferred compared to a bare-metal stent (BMS) because it is proven to improve survival, particularly guided by IVUS. It is also associated with fewer adverse cardiovascular events and a low restenosis risk in the atherosclerosis population; 21 ' 22 further studies are needed to confirm its application in the LMCA compression due to $\mathrm{PH}$ population. The choice of a newer-generation DES containing zotarolimus was based on the safety and effectiveness of the individualized approach to shortened dual anti-platelet duration in selected patients undergoing PCI, such as in high bleeding-risk patients, but this also needs further studies to assure safety in the PH population [23, 24]. The use of IVUS in this condition is to determine the characteristics of compression (whether there is an atherosclerotic plaque), precise part of involvement, ischemia burden of the stenosis estimation, stent optimization, and adequate expansion and apposition of the stent after LM PCI $[21,25]$.

The cornerstone of management is to manage the aetiology, which is the CHD. Defect closure is recommended to hopefully improve both PAp and LMCA compression, but further studies are needed to confirm this hypothesis [25]. Mainstay treatment of Eisenmenger syndrome has evolved in the past decade and is divided into several steps, including supportive therapy with oral anticoagulants, diuretics or oxygen therapy, with referral to $\mathrm{PH}$ centres to perform vasoreactivity testing to assess suitability for surgical repair $[26,27]$. The use of PH targeted therapy such as endothelin receptor antagonists (ERA), phosphodiesterase type 5 (PDE-5) inhibitors, and prostacyclin analogues as monotherapy or drug combination are class I recommendations in pulmonary arterial hypertension (PAH) therapy according to the WHO functional classes stated in the ESC guidelines for the diagnosis and treatment of $\mathrm{PH}$. Those drugs reduce the pressure elevation and diameter of the PA and are proven to improve angina symptoms. Invasive management such as balloon atrial septostomy (BAS) and lung transplantation are also considered after inadequate response to optimal medical treatment [3].

A surgical approach with aneurysmorrhaphy to reduce the PA diameter, aneurysmectomy to repair or replace the artery, and double-lung or heart-lung transplantation is recommended in PA aneurysm with compression of adjacent structures, although it carries a very high surgical risk [28, 29]. Novel PA reduction plasty is also the current preferred choice. The techniques include internal plication and outer layer reinforcement to hopefully reduce pressure, although further studies are necessary to establish this recommendation $[29,30]$.

LMCA compression is a complication that should be suspected in patients with Eisenmenger syndrome presenting with angina symptoms. Non-invasive modalities such as contrast-enhanced CT are recommended to detect both $\mathrm{PH}$ features and coronary artery 


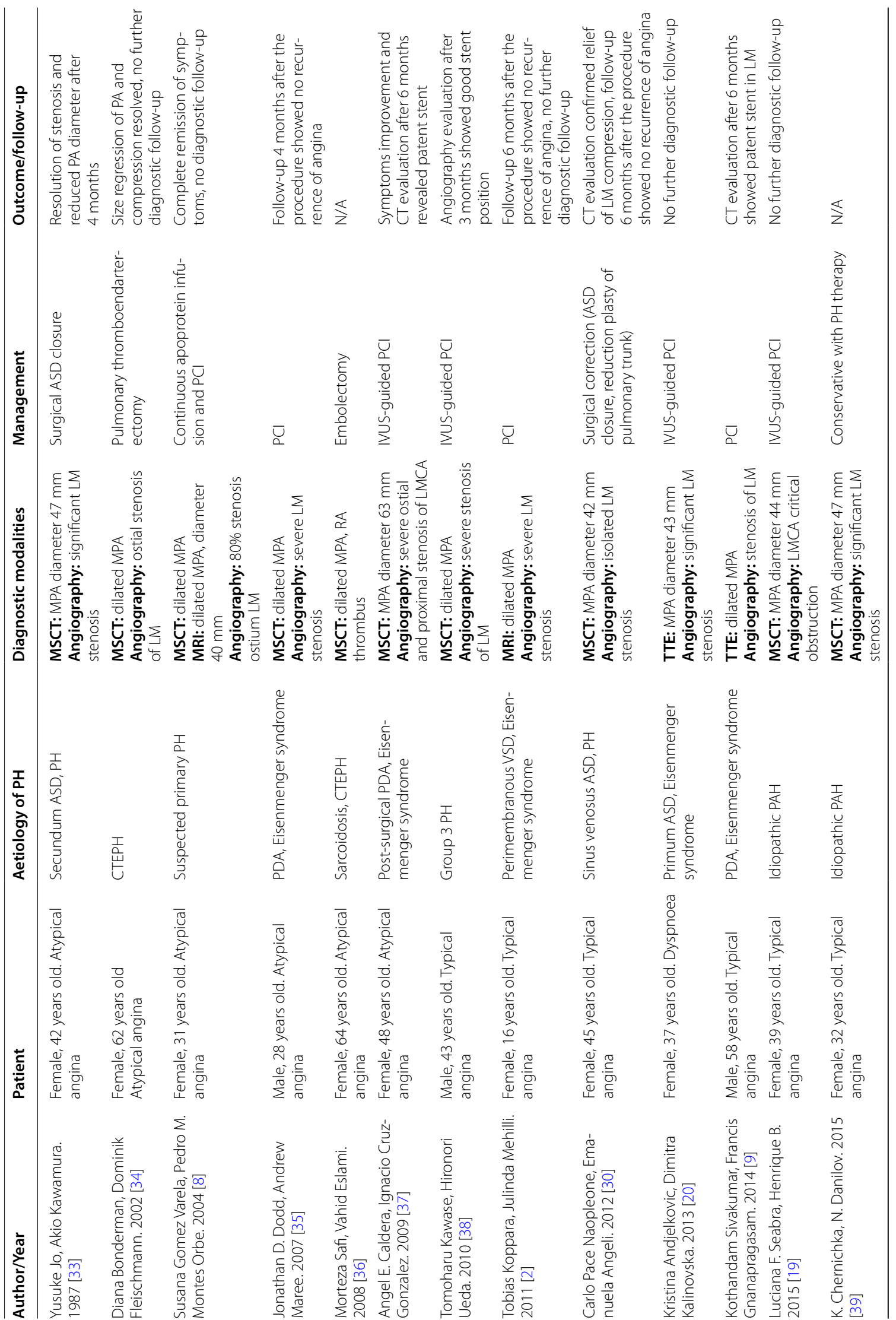




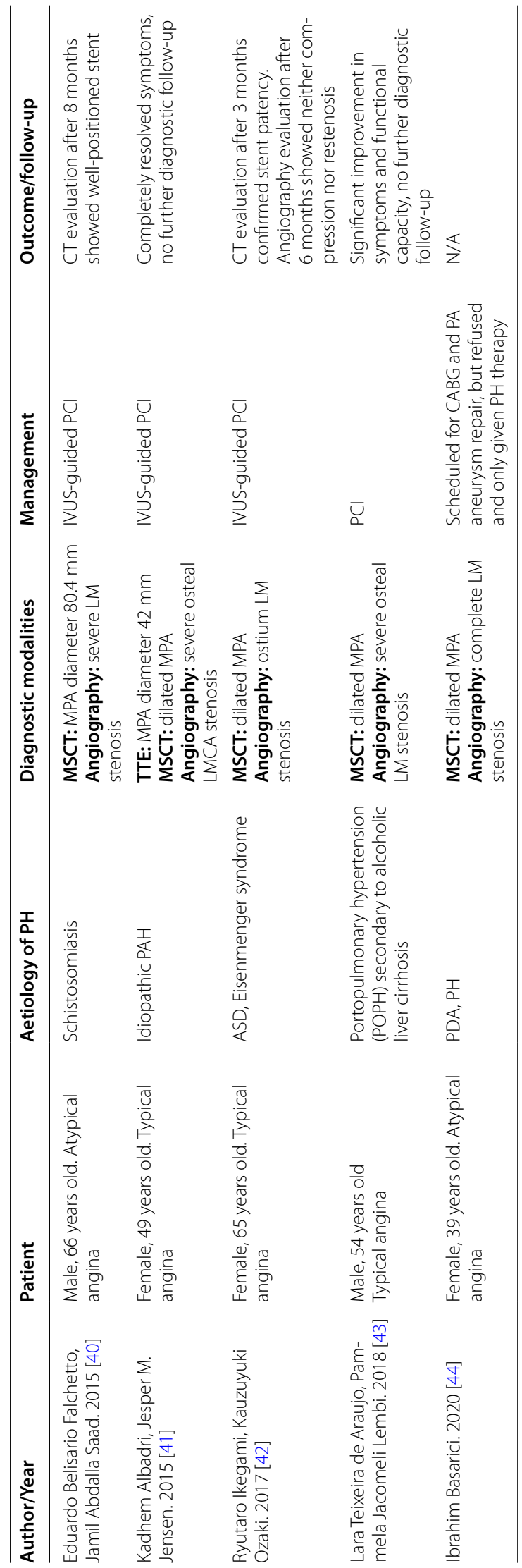


compression, with acceptable accuracy. Invasive modalities also play an important role in confirming the diagnosis and as ideal management. An LM stenting procedure is considered the best therapeutic approach to improve long-term patient outcomes.

\section{Strengths}

We successfully diagnosed and treated a patient with LM compression due to PA dilation in Eisenmenger syndrome, with a good outcome.

\section{Limitations}

We present only one patient in this case report, and no specific guidelines exist for management. We also have limited resources, such as $\mathrm{PH}$ drugs, which are unavailable in our country, and human resources specializing in surgical procedures to optimize the management.

\section{Learning points}

In Eisenmenger syndrome patients presenting with angina, mechanical complications such as LMCA compression should be considered as an aetiology. Proper evaluation and management are essential for a better prognosis.

\begin{abstract}
Abbreviations
PH: Pulmonary hypertension; PAH: Pulmonary arterial hypertension; CHD: Congenital heart disease; PA: Pulmonary artery; ASD: Atrial septal defect; ECG: Electrocardiogram; RAD: Right axis deviation; RVH: Right ventricular hypertrophy; RBBB: Right bundle branch block; TTE: Transthoracic echocardiography; LV: Left ventricle; RA: Right atrium; RV: Right ventricle; LA: Left atrium; TR: Tricuspid velocity; MPA: Main pulmonary artery; PAp: Pulmonary artery pressure; RHC: Right heart catheterization; PVR: Pulmonary vascular resistance; mPAp: Mean pulmonary artery pressure; LM: Left main; LMCA: Left main coronary artery; CT: Computerized tomography; IVUS: Intravascular ultrasound; CAD: Coronary artery disease; CPB: Cardiopulmonary bypass; CABG: Coronary artery bypass graft; DES: Drug-eluting stent; BMS: Bare-metal stent; ERA: Endothelin receptor antagonists; PDE-5: Phosphodiesterase type 5; BAS: Balloon atrial septostomy.
\end{abstract}

\section{Acknowledgements}

Not applicable.

\section{Authors' contributions}

CJC: Conceptualization, data curation, writing (original draft, review and editing), supervision. FF: Conceptualization, data curation, writing (original draft, review and editing). IA: Conceptualization, data curation. AS: Conceptualization, data curation, review and editing. NYK: Data curation, review and editing. AA: Data curation, review and editing. AFY:Writing (review and editing), supervision. All authors have read and approved the manuscript.

\section{Funding}

The authors received no specific funding.

Availability of data and materials

Not applicable.

\section{Declarations}

Ethics approval and consent to participate

Not applicable.

\section{Consent for publication}

Written informed consent was obtained from the patient for publication of this case report and any accompanying images. A copy of the written consent is available for review by the Editor of this journal.

\section{Competing interests}

The authors declare that they have no competing interests.

\section{Author details}

${ }^{1}$ Congenital Heart Disease Division, Department of Cardiology and Vascular Medicine, University of Padjadjaran, Hasan Sadikin General Hospital, J. Pasteur No. 38, Bandung 40161, Indonesia. ${ }^{2}$ Department of Cardiology and Vascular Medicine, University of Padjadjaran, Hasan Sadikin General Hospital, Bandung, Indonesia. ${ }^{3}$ Cardiology Intervention Division, Department of Cardiology and Vascular Medicine, University of Padjadjaran, Hasan Sadikin General Hospital, Bandung, Indonesia. ${ }^{4}$ Cardiovascular Imaging Division, Department of Cardiology and Vascular Medicine, University of Padjadjaran, Hasan Sadikin General Hospital, Bandung, Indonesia.

Received: 28 June 2021 Accepted: 22 February 2022

Published online: 05 March 2022

\section{References}

1. Raymond TE, Khabbaza JE, Yadav R, Tonelli AR. Significance of main pulmonary artery dilation on imaging studies. Ann Am Thorac Soc. 2014;11:1623-32.

2. Koppara T, Mehilli J, Hager A, Kaemmerer H. Left main coronary artery compression in a young woman with Eisenmenger syndrome. Heart Asia. 2011:3:13-5

3. Galiè N, Humbert M, Vachiery JL, Gibbs S, Lang I, Torbicki A, et al. 2015 ESC/ERS Guidelines for the diagnosis and treatment of pulmonary hypertension. Eur Heart J. 2016;37:67-119.

4. Chemia D, Castelain V, Hervé P, Lecarpentier Y, Brimioulle S. Haemodynamic evaluation of pulmonary hypertension. Eur Respir J. 2002;20:1314-31.

5. Badagliacca R, Poscia R, Pezzuto B, Papa S, Nona A, Mancone M, et al. Pulmonary arterial dilatation in pulmonary hypertension: Prevalence and prognostic relevance. Cardiology. 2012;121:76-82.

6. Augustine DX, Augustine DX, Coates-bradshaw LD, Willis J, Harkness A, Ring $L$, et al. Echocardiographic assessment of pulmonary hypertension: a guideline protocol from the British Society of Echocardiography. Echo Res Pract. 2018;5:11-24.

7. Viar WN, Harrison TR. Chest pain in association with pulmonary hypertension; its similarity to the pain of coronary disease. Circulation. 1952;5:1-11.

8. Gómez Varela S, Montes Orbe PM, Alcíbar Villa J, Egurbide MV, Sainz I, Barrenetxea Benguría Jl. Stenting in primary pulmonary hypertension with compression of the left main coronary artery. Rev Española Cardiol (English Ed). 2004;57:695-8.

9. Sivakumar K, Rajan M, Francis G, Murali K, Bashi V. Extrinsic compression of the left coronary ostium by the pulmonary trunk: Management in a case of eisenmenger syndrome. Texas Hear Inst J. 2010;37:95-8.

10. Kajita LJ, Martinez EE, Ambrose JA, Lemos PA, Esteves A, Da GMN, et al. Extrinsic compression of the left main coronary artery by a dilated pulmonary artery: clinical, angiographic, and hemodynamic determinants. Catheter Cardiovasc Interv. 2001;52:49-54.

11. Vaseghi M, Lee MS, Currier J, Tobis J, Shapiro S, Aboulhosn J. Percutaneous intervention of left main coronary artery compression by pulmonary artery aneurysm. Catheter Cardiovasc Interv. 2010;76:352-6.

12. Kandathil A, Chamarthy M. Pulmonary vascular anatomy \& anatomical variants. Cardiovasc Diagn Ther. 2018;8:201-7.

13. Joshi SD, Joshi SS, Athavale SA. Origins of the coronary arteries and their significance. Clinics. 2010;65:79-84.

14. Corday E, Gold H, Kaplan L. Coronary artery compression; an explanation for the cause of coronary insufficiency in pulmonary hypertension. Trans Am Coll Cardiol. 1957;7:93-103.

15. Galiè N, Saia F, Palazzini M, Manes A, Russo V, Bacchi Reggiani ML, et al. Left main coronary artery compression in patients with pulmonary arterial hypertension and angina. J Am Coll Cardiol. 2017;69:2808-17. https:// doi.org/10.1016/j.jacc.2017.03.597. 
16. Lee SE, Im JH, Sung JM, Cho IJ, Shim CY, Hong GR, et al. Detection of mechanical complications related to the potential risk of sudden cardiac death in patients with pulmonary arterial hypertension by computed tomography. Int J Cardiol. 2017;243:460-5. https://doi.org/10.1016/j. ijcard.2017.05.090.

17. Harjola VP, Mebazaa A, Čelutkiene J, Bettex D, Bueno H, Chioncel O, et al. Contemporary management of acute right ventricular failure: a statement from the Heart Failure Association and the working group on pulmonary circulation and right ventricular function of the European Society of Cardiology. Eur J Heart Fail. 2016;18:226-41.

18. Fernandes F, Alam M, Smith S, Khaja F. The role of transesophageal echocardiography in identifying anomalous coronary arteries. Circulation. 1993;88:2532-40.

19. Seabra LF, Ribeiro HB, de Barros e Silva PGM, Rodrigues MJ, Spadaro $A G$, Conejo $F$, et al. Left main ostial compression in a patient with pulmonary hypertension: dynamic findings by IVUS. Am J Case Rep. 2015;16:899-903.

20. Andjelkovic K, Kalimanovska-Ostric D, Djukic M, Vukcevic V, Menkovic N, Mehmedbegovic Z, et al. Two rare conditions in an Eisenmenger patient: left main coronary artery compression and Ortner's syndrome due to pulmonary artery dilatation. Heart Lung. 2013;42:382-6.

21. Levine GN, Bates ER, Blankenship JC, Bailey SR, Bittl JA, Cercek B, et al. 2011 ACCF/AHA/SCAI guideline for percutaneous coronary intervention a report of the American College of Cardiology Foundation/ American Heart Association Task Force on Practice Guidelines and the Society for Cardiovascular Angiography and Interventions. Circulation. 2011;124:574-651.

22. Ramadan R, Boden WE, Kinlay S. Management of left main coronary artery disease. J Am Heart Assoc. 2018;7:e008151.

23. Kandzari DE, Kirtane AJ, Windecker S, Latib A, Kedhi E, Mehran R, et al. One-Month dual antiplatelet therapy following percutaneous coronary intervention with zotarolimus-eluting stents in high-bleeding-risk patients. Circ Cardiovasc Interv. 2020;13(11):e009565.

24. Iqbal J, Serruys PW, Silber S, Kelbaek H, Richardt G, Morel MA, et al. Comparison of zotarolimus-and everolimus-eluting coronary stents: Final 5-year report of the RESOLUTE all-comers trial. Circ Cardiovasc Interv. 2015;8:e002230

25. Labin JE, Saggar R, Yang EH, Lluri G, Sayah D, Channick R, et al. Left main coronary artery compression in pulmonary hypertension. Catheter Cardiovasc Interv. 2020. https://doi.org/10.1002/ccd.29401.

26. Cordina RL, Celermajer DS. Therapeutic approaches in adults with congenital heart disease-associated pulmonary arterial hypertension. Eur Respir Rev. 2010;19:300-7.

27. Tonelli AR, Alnuaimat H, Mubarak K. Pulmonary vasodilator testing and use of calcium channel blockers in pulmonary arterial hypertension. Respir Med. 2010;104:481-96. https://doi.org/10.1016/j.rmed.2009.11.015.

28. Kreibich M, Siepe M, Kroll J, Höhn R, Grohmann J, Beyersdorf F. Aneurysms of the pulmonary artery. Circulation. 2015;131:310-6.

29. Shin HJ, Suh YJ. Novel pulmonary artery reduction plasty for pulmonary artery aneurysm with pulmonary arterial hypertension. World J Pediatr Congenit Heart Surg. 2016;7:96-9.

30. Napoleone CP, Angeli E, Oppido G, Turci S, Gargiulo G. Left main coronary artery stenosis secondary to severe pulmonary artery dilation. Asian Cardiovasc Thorac Ann. 2012;20:708-10.

31. Demerouti EA, Manginas AN, Athanassopoulos GD, Karatasakis GT. Complications leading to sudden cardiac death in pulmonary arterial hypertension. Respir Care. 2013;58:1246-54.

32. Kaemmerer H, Mebus S, Schulze-Neick I, Eicken A, Trindade PT, Hager A, et al. The adult patient with eisenmenger syndrome: a medical update after dana point part I: epidemiology, clinical aspects and diagnostic options. Curr Cardiol Rev. 2010;6:343-55.

33. Jo Y, Kawamura A, Jinzaki M, Kohno T, Anzai T, Iwanaga S, et al. Extrinsic compression of the left main coronary artery by atrial septal defect. Ann Thorac Surg. 2008;86:1987-9. https://doi.org/10.1016/j.athoracsur.2008. 05.046 .

34. Bonderman D, Fleischmann D, Prokop M, Klepetko W, Lang IM. Left main coronary artery compression by the pulmonary trunk in pulmonary hypertension. Circulation. 2002;105:265. https://doi.org/10.1161/hc0202. 100239.

35. Dodd JD, Maree A, Palacios I, De Moor MM, Mooyaart EAQ, Shapiro $M D$, et al. Left main coronary artery compression syndrome: evaluation with 64-slice cardiac multidetector computed tomography. Circulation. 2007;115:10-1.

36. Safi M, Eslami V, Shabestari AA, Saadat H, Namazi MH, Vakili H, et al. Extrinsic compression of left main coronary artery by the pulmonary trunk secondary to pulmonary hypertension documented using 64-slice multidetector computed tomography coronary angiography. Clin Cardiol. 2009;32:426-8.

37. Caldera AE, Cruz-Gonzalez I, Bezerra HG, Cury RC, Palacios IF, Cockrill BA, et al. Endovascular therapy for left main compression syndrome: case report and literature review. Chest. 2009;135:1648-50.

38. Kawase T, Ueda H, Watanabe N, Motoda C, Takeda R, Mito S, et al. A case of acute coronary syndrome caused by extrinsic compression of the left main coronary artery due to pulmonary hypertension. J Cardiol Cases. 2010;2:e154-8. https://doi.org/10.1016/j.jccase.2010.06.002.

39. Chernichka K, Danilov N, Matchin Y, Martynyuk T, Mitroshkin M, Fedotenkov I, et al. PP.22.07: left main coronary artery compression syndrome in severe pulmonary arterial hypertension: the evaluation of stent placement necessity based on intravascular ultrasound data. J Hypertens. 2015;33:e332.

40. Falchetto EB, Saad JA, De Almeida FL, Washizu EKM, Mandil A. Extrinsic obstruction of the left main coronary artery due to pulmonary artery dilation associated with schistosomiasis. Rev Bras Cardiol Invasiva. 2015;23:148-51. https://doi.org/10.1016/j.rbciev.2015.12.016.

41. Albadri K, Jensen JM, Christiansen EH, Mellemkjær S, Nielsen-Kudsk JE. Left main coronary artery compression in pulmonary arterial hypertension. Pulm Circ. 2015;5:734-6.

42. Ikegami R, Ozaki K, Ozawa T, Hirono S, Ito M, Minamino T. Percutaneous coronary intervention for a patient with left main coronary compression syndrome. Intern Med. 2018;57:1421-4.

43. de Araújo IT, Lembi PJ, Falchetto EB, Corrêa RDA. Left main coronary artery compression in a patient with portopulmonary hypertension. J Bras Pneumol. 2018;44:337-8.

44. Başarıcı I. Left main coronary artery occlusion by external compression with a large pulmonary artery in Eisenmenger syndrome. Anatol J Cardiol. 2020;23:55-6.

\section{Publisher's Note}

Springer Nature remains neutral with regard to jurisdictional claims in published maps and institutional affiliations.

\footnotetext{
Ready to submit your research? Choose BMC and benefit from:

- fast, convenient online submission

- thorough peer review by experienced researchers in your field

- rapid publication on acceptance

- support for research data, including large and complex data types

- gold Open Access which fosters wider collaboration and increased citations

- maximum visibility for your research: over 100M website views per year
}

At BMC, research is always in progress.

Learn more biomedcentral.com/submissions 